\title{
A Prática da Política Nacional de Humanização em um Hospital Público de Manaus
}

\author{
Palheta, Rosiane Pinheiro; Costa, Roberta Justina da \\ Fundação Hospital Adriano Jorge - anypinheiro@hotmail.com
}

INTRODUÇÃO: o trabalho trata de uma experiência vivenciada no Hospital Adriano Jorge em Manaus cujo objetivo volta-se primeiramente para os trabalhadores de saúde. Os trabalhadores são sensibilizados através de oficinas realizadas pelo Grupo de Trabalho de Humanização-GTH formado com o intuito de disparar a Política Nacional de Humanização e seus dispositivos. OBJETIVOS: Sensibilizar os funcionários sobre a importância da PNH; Articular, sensibilizar e envolver os gestores e profissionais de saúde nos objetivos, princípios e diretrizes da $\mathrm{PNH}$ e avaliar os primeiros impactos da intervenção a partir da própria fala dos profissionais treinados. MÉTODOS: a metodologia foi construída gradativamente ao longo das duas etapas, a de encontros de capacitação com profissionais que formaram o Grupo de Trabalho em Humanização e a de oficinas de sensibilização em humanização com os trabalhadores de saúde. o trabalho procurou valorizar a participação dos envolvidos através das atividades interativas, o uso de dinâmicas, relato de experiência e repasse das informações sobre a Política Nacional de Humanização. RESULTADOS: Realização de 15 oficinas com os profissionais de saúde e funcionários da FHAJ; Maior envolvimento da equipe multiprofissional; Reflexão sobre o processo de trabalho; mudanças de postura junto aos colegas e aos usuários. a importância dos encontros é evidenciada na fala dos funcionários que passam pelas oficinas: "Estou saindo daqui renovada"; "Deveria haver sempre encontros como este"; "Há muito tempo queria falar o que falei hoje", evidenciam a importância do trabalho e do "contágio", que tem sido desencadeado pela proposta pedagógica que parte da realidade e valoriza o conhecimento dos envolvidos no processo educativo. CONCLUSÕES: Os resultados obtidos foram: a Formação do Grupo de Trabalho em Humanização; a realização de 34 oficinas com a participação de 339 servidores, abordando conteúdos e temas relacionados à $\mathrm{PNH}$; e um Diagnóstico da situação. As oficinas de humanização têm sido um espaço de encontro, de produção e socialização de saberes e experiências, uma possibilidade de expor problemas e, sobretudo, alternativas de solucioná-los vindas dos trabalhadores de saúde.

Palheta, Rosiane Pinheiro; Costa, Roberta Justina da. A Prática da Política Nacional de Humanização em um Hospital Público de Manaus. In: Anais do Congresso Internacional de Humanidades \& Humanização em Saúde [= Blucher Medical Proceedings, num.2, vol.1]. São Paulo: Editora Blucher, 2014. ISSN 2357-7282 DOI 10.5151/medpro-cihhs-10388 